\title{
Expression of adhesion molecules and transforming growth factor- $\beta$ in pleomorphic carcinomas of the lung
}

\author{
AKIRA OKIMURA $^{1}$, NOBUYUKI TERADA ${ }^{2}$, MASAKI HATA ${ }^{2}$, KUNIMITSU KAWAHARA ${ }^{1}$, \\ TERUO IWASAKI ${ }^{3}$, MITSUNORI OOTA $^{3}$ and HIROSHI HIRANO ${ }^{4}$
}

\begin{abstract}
Departments of ${ }^{1}$ Pathology and ${ }^{3}$ Surgery, Osaka Prefectural Medical Center for Respiratory and Allergic Diseases, Habikino, Osaka 583-8588; ${ }^{2}$ Department of Pathology, Hyogo College of Medicine, Nishinomiya, Hyogo 663-8501; ${ }^{4}$ Department of Pathology, Nippon Steel Hirohata Hospital, Hirohata, Hyogo 671-1122, Japan
\end{abstract}

Received June 23, 2010; Accepted August 9, 2010

DOI: $10.3892 / \mathrm{ol} .2010 .166$

\begin{abstract}
Pleomorphic carcinoma (PC) of the lung consists of an epithelial component showing the histology of poorly differentiated non-small cell carcinoma of the lung and a sarcomatous component, that is more aggressive compared to non-small cell carcinoma of the lung. To determine the differences between an epithelial component of PC and poorly differentiated non-small cell carcinoma, the expression of adhesion molecules (E-cadherin, $\beta$-catenin and $\mathrm{N}$-cadherin) and transforming growth factor- $\beta$ (TGF- $\beta$ ) was compared immunohistochemically among 14 poorly differentiated adenocarcinomas of the lung (PDAs) and 14 PCs of the lung, with an epithelial component, showing the histology of PDA. Expression levels of E-cadherin and $\beta$-catenin were significantly lower in epithelial or sarcomatous components of PCs than in PDAs while that of TGF- $\beta$ was significantly higher in epithelial components of PCs than in PDAs. No significant difference was found in incidences of the expression of these molecules between epithelial and sarcomatous components of PCs. No significant difference was noted in the expression level of N-cadherin among PDAs and epithelial and sarcomatous components of PCs. The present results showed that E-cadherin and $\beta$-catenin expression is reduced and TGF- $\beta$ expression is increased in epithelial components of PCs with the same histology as PDA when compared to PDAs, suggesting that an epithelial component of $\mathrm{PC}$ is distinct from non-small cell carcinoma with the same histology.
\end{abstract}

\section{Introduction}

Pleomorphic carcinoma (PC) of the lung, one of the sarcomatoid carcinomas (1), comprises both an epithelial component

Correspondence to: Dr Akira Okimura, Department of Pathology, Osaka Prefectural Medical Center for Respiratory and Allergic Diseases, 3-7-1 Habikino-cho, Habikino, Osaka 583-8588, Japan E-mail: okimuraa@ra.opho.jp

Key words: pleomorphic carcinoma, lung, E-cadherin, $\beta$-catenin, transforming growth factor- $\beta$ and a sarcomatous component of spindle and/or giant cells or of spindle or giant cells only and an aggressive cancer, with the prognosis of PCs as well as sarcomatoid carcinomas being worse than that of non-small cell carcinomas $(2,3)$. The epithelial component of PC shows the same histology as poorly differentiated non-small cell carcinoma of the lung (1). Przygodzki et al (4), however, showed that mutation frequencies and patterns for p53 and K-ras were different between the epithelial components of PCs and non-small cell carcinomas, indicating that epithelial components of PCs are distinct from poorly differentiated non-small cell carcinomas. However, the differences between an epithelial component of PC and a corresponding poorly differentiated non-small cell carcinoma have yet to be clarified.

Cell adhesion molecules are expressed in various types of cancer and their altered expression is associated with the dedifferentiation, invasion and metastasis of cancer cells (5-8). E-cadherin forms a calcium-dependent cell-cell adhesion complex together with $\beta$-catenin which binds to the intracellular domain of E-cadherin as well as actin filaments, connecting this adhesion complex to the cell cytoskeleton (5-8). The E-cadherin- $\beta$-catenin complex is essential for the formation of stable cell-cell adhesion and its reduced expression has been shown to be associated with dedifferentiation, metastasis and poor prognosis in various types of cancer including lung cancer (5-8). On the other hand, the up-regulated expression of $\mathrm{N}$-cadherin, another calcium-dependent adhesion molecule, has been shown to be associated with the invasive and metastatic potential of cancers (9-12). It has been shown that the overexpression of $\mathrm{N}$-cadherin increases the migration, invasion and metastasis of breast cancer cells through the $\mathrm{N}$-cadherin-mediated interaction of cancer to stromal cells (10).

Cancer cells of an epithelial cell phenotype often change into fibroblast-like cells expressing a mesenchymal cell phenotype. This phenomenon, known as epithelial-mesencymal transition, promotes the invasion and metastasis of cancer cells (13-15). Transforming growth factor (TGF)- $\beta$ is one of the epithelial-mesencymal transition-inducing factors $(14,16,17)$. TGF- $\beta$ has been reported to be associated with poor prognosis of patients with certain types of cancer including lung cancer (18-22). 
Table I. Antibodies used for the immunohistochemistry analysis.

\begin{tabular}{lcccc}
\hline Antigen & Clone & Source & Dilution & Antigen retrieval \\
\hline Pankeratin & Polyclonal & Dakocytomation, Glostrup, Denmark & $1: 500$ & Protease \\
EMA & E29 & Dakocytomation, Glostrup, Denmark & $1: 80$ & None \\
CEA & Polyclonal & Dakocytomation, Glostrup, Denmark & $1: 1000$ & None \\
E-cadherin & $36 B 5$ & Novocastra, Newcastle upon Tyne, UK & $1: 50$ & MW \\
$\beta$-catenin & $17 C 2$ & Novocastra, Newcastle upon Tyne, UK & $1: 80$ & MW \\
N-cadherin & IAR06 & Novocastra, Newcastle upon Tyne, UK & $1: 100$ & MW \\
TGF- $\beta$ & TGFB17 & Novocastra, Newcastle upon Tyne, UK & $1: 40$ & MW
\end{tabular}

EMA, epithelial membrane antigen; CEA, carcinoembryonic antigen; TGF- $\beta$, transforming growth factor- $\beta$; MW, microwave.

Table II. Clinical findings of 14 patients with pleomorphic carcinomas.

\begin{tabular}{|c|c|c|c|c|c|c|c|c|c|c|}
\hline \multirow[t]{2}{*}{ Patient } & \multirow{2}{*}{$\begin{array}{l}\text { Age } \\
\text { (years) }\end{array}$} & \multirow[t]{2}{*}{ Gender } & \multirow[t]{2}{*}{ Location } & \multirow{2}{*}{$\begin{array}{l}\text { Size } \\
(\mathrm{mm})\end{array}$} & \multirow[t]{2}{*}{ pStage } & \multirow[t]{2}{*}{ Treatment } & \multicolumn{2}{|c|}{ Histology } & \multirow{2}{*}{$\begin{array}{c}\mathrm{E} / \mathrm{S} \\
\text { percentage }\end{array}$} & \multirow[t]{2}{*}{ Follow-up } \\
\hline & & & & & & & $\mathrm{E}$ & $\mathrm{S}$ & & \\
\hline 1 & 74 & M & LLL & $47 \times 63 \times 70$ & IIIa & Lob.+Rad. & PDA & Spindle & $20 / 60$ & 11 mo.dead \\
\hline 2 & 71 & $\mathrm{M}$ & RUL & $42 \times 23$ & IV & Lob. & PDA & Spindle & $80 / 20$ & 5 mo.dead \\
\hline 3 & 58 & $\mathrm{M}$ & RML & $90 \times 76$ & $\mathrm{IIb}$ & Lob. & PDA & Spindle+giant & $40 / 60$ & 3 mo.alive \\
\hline 4 & 52 & $\mathrm{M}$ & LUL & $32 \times 30$ & IIIa & Lob.+Che. & PDA & Spindle & $80 / 20$ & 11 mo.dead \\
\hline 5 & 70 & M & RLL & $45 \times 23$ & $\mathrm{Ib}$ & Lob. & PDA & Spindle+giant & $20 / 80$ & 2 mo.dead \\
\hline 6 & 75 & M & RUL & $60 \times 50$ & $\mathrm{IIb}$ & Lob. & PDA & Spindle+giant & $10 / 90$ & 6 mo.dead \\
\hline 7 & 68 & M & LUL & 80 & $\mathrm{IIb}$ & Lob.+Che. & PDA & Giant & $10 / 90$ & 3 mo.dead \\
\hline 8 & 76 & M & LUL & $40 \times 30 \times 35$ & IIIa & Lob.+Rad. & PDA & Giant & $10 / 90$ & 11 yr.dead \\
\hline 9 & 67 & $\mathrm{M}$ & RUL & $45 \times 30 \times 48$ & $\mathrm{IIb}$ & Lob. & PDA & Spindle & $20 / 80$ & 5 mo.dead \\
\hline 10 & 69 & $\mathrm{M}$ & LLL & $50 \times 30$ & $\mathrm{IIb}$ & Lob. & PDA & Spindle+giant & $10 / 90$ & 3 mo.alive \\
\hline 11 & 44 & M & LUL & $72 \times 65 \times 70$ & $\mathrm{IIb}$ & Lob.+Rad. & PDA & Spindle+giant & $20 / 80$ & 9 mo.dead \\
\hline 12 & 48 & M & LUL & $60 \times 55 \times 80$ & $\mathrm{IIb}$ & Lob.+Che & PDA & Spindle+giant & $10 / 90$ & 7 mo.alive \\
\hline 13 & 64 & M & LUL & $72 \times 46$ & $\mathrm{IIb}$ & Lob. & PDA & Spindle+giant & $20 / 80$ & 6 mo.dead \\
\hline 14 & 41 & M & LUL & $35 \times 25 \times 30$ & $\mathrm{IIb}$ & Lob.+Che. & PDA & Giant & $20 / 80$ & 6 mo.dead \\
\hline
\end{tabular}

M, male; RUL, right upper lobe; RML, right middle lobe; RLL, right lower lobe; LUL, left upper lobe; LLL, left lower lobe; Lob., lobectomy; Rad., radiation; Che., chemotherapy; Spindle, Spindle cell type; giant, giant cell type; mo., months; yr., years; E, epithelial component; $\mathrm{S}$, sarcomatous component; PDA, poorly differentiated adenocarcinoma.

To elucidate the differences between an epithelial component of PC and a corresponding poorly differentiated non-small cell carcinoma, the expression of the above-mentioned molecules was investigated immunohistochemically in poorly differentiated adenocarcinomas of the lung and PCs with an epithelial component exhibiting the same histology as poorly differentiated adenocarcinoma.

\section{Materials and methods}

Subjects. A total of 14 PC specimens and 14 specimens of poorly differentiated adenocarcinomas were used for this study. The specimens were obtained from lung tissues resected at the Osaka Prefectural Medical Center for Respiratory and Allergic Diseases. Written consent was obtained from each patient prior to the operation and the anonymous usage of tissue samples for pathological studies was permitted. This study was approved by the Ethics Committee of Osaka Prefectural Medical Center for Respiratory and Allergic Diseases. The PC specimens contained epithelial and sarcomatous components; the epithelial components showed a histology of poorly differentiated adenocarcinoma. Poorly differentiated adenocarcinomas 1, 6, 1, 5 and 1 were at pStages Ia, Ib, IIa, IIb and IV, respectively.

Immunohistochemistry. Details of the primary antibodies used and their dilutions are shown in Table I. Immunohistochemical staining was performed using formalin-fixed, paraffinembedded tissue sections with an EnVision detection system (EnVision+; Dakocytomation, Glostrup, Denmark). The sections were deparaffinized and rehydrated, and endogenous peroxidase activity was blocked using $0.03 \% \mathrm{H}_{2} \mathrm{O}_{2}$. 
Table III. Expression of epithelial markers and vimentin in pleomorphic carcinomas and poorly differentiated adenocarcinomas of the lung.

\begin{tabular}{|c|c|c|c|c|c|c|c|c|}
\hline \multirow[b]{2}{*}{ Case } & \multicolumn{2}{|c|}{ Cytokeratin } & \multicolumn{2}{|c|}{ EMA } & \multicolumn{2}{|c|}{ CEA } & \multicolumn{2}{|c|}{ Vimentin } \\
\hline & E & $\mathrm{S}$ & E & $\mathrm{S}$ & E & $\mathrm{S}$ & E & $\mathrm{S}$ \\
\hline \multicolumn{9}{|c|}{ Pleomoprhic carcinoma } \\
\hline 1 & $(-)$ & $(-)$ & $(3+)$ & $(3+)$ & $(3+)$ & $(-)$ & $(2+)$ & $(3+)$ \\
\hline 2 & $(3+)$ & $(3+)$ & $(3+)$ & $(1+)$ & $(-)$ & $(-)$ & $(-)$ & $(2+)$ \\
\hline 3 & $(3+)$ & $(-)$ & $(-)$ & $(-)$ & $(-)$ & $(-)$ & $(-)$ & $(3+)$ \\
\hline 4 & $(3+)$ & $(3+)$ & $(3+)$ & $(3+)$ & $(3+)$ & $(-)$ & $(-)$ & $(3+)$ \\
\hline 5 & $(3+)$ & $(3+)$ & $(-)$ & $(-)$ & $(3+)$ & $(2+)$ & $(-)$ & $(3+)$ \\
\hline 6 & $(3+)$ & $(3+)$ & $(3+)$ & $(-)$ & $(3+)$ & $(2+)$ & $(-)$ & $(3+)$ \\
\hline 7 & $(3+)$ & $(2+)$ & $(3+)$ & $(3+)$ & $(-)$ & $(-)$ & $(-)$ & $(3+)$ \\
\hline 8 & $(3+)$ & $(-)$ & $(3+)$ & $(2+)$ & $(1+)$ & $(-)$ & $(-)$ & $(2+)$ \\
\hline 9 & $(3+)$ & $(-)$ & $(-)$ & $(-)$ & $(2+)$ & $(1+)$ & $(-)$ & $(3+)$ \\
\hline 10 & $(3+)$ & $(3+)$ & $(3+)$ & $(3+)$ & $(-)$ & $(-)$ & $(-)$ & $(3+)$ \\
\hline 11 & $(3+)$ & $(2+)$ & $(3+)$ & $(2+)$ & $(-)$ & $(-)$ & $(-)$ & $(3+)$ \\
\hline 12 & $(3+)$ & $(2+)$ & $(3+)$ & $(2+)$ & $(-)$ & $(-)$ & $(-)$ & $(3+)$ \\
\hline 13 & $(3+)$ & $(3+)$ & $(3+)$ & $(3+)$ & $(3+)$ & $(2+)$ & $(-)$ & $(3+)$ \\
\hline 14 & $(-)$ & $(3+)$ & $(3+)$ & $(3+)$ & $(-)$ & $(-)$ & $(-)$ & $(-)$ \\
\hline \multicolumn{9}{|c|}{ Poorly differentiated adenocarcinoma } \\
\hline 1 & $(1+)$ & & $(3+)$ & & $(1+)$ & & $(-)$ & \\
\hline 2 & $(3+)$ & & $(3+)$ & & $(3+)$ & & $(-)$ & \\
\hline 3 & $(3+)$ & & $(3+)$ & & $(3+)$ & & $(-)$ & \\
\hline 4 & $(3+)$ & & $(3+)$ & & $(2+)$ & & $(-)$ & \\
\hline 5 & $(3+)$ & & $(3+)$ & & $(2+)$ & & $(-)$ & \\
\hline 6 & $(3+)$ & & $(3+)$ & & $(1+)$ & & $(-)$ & \\
\hline 7 & $(3+)$ & & $(3+)$ & & $(-)$ & & $(-)$ & \\
\hline 8 & $(3+)$ & & $(3+)$ & & $(1+)$ & & $(-)$ & \\
\hline 9 & $(3+)$ & & $(-)$ & & $(-)$ & & $(-)$ & \\
\hline 10 & $(3+)$ & & $(3+)$ & & $(3+)$ & & $(-)$ & \\
\hline 11 & $(3+)$ & & $(3+)$ & & $(2+)$ & & $(-)$ & \\
\hline 12 & $(3+)$ & & $(3+)$ & & $(3+)$ & & $(-)$ & \\
\hline 13 & $(3+)$ & & $(3+)$ & & $(1+)$ & & $(-)$ & \\
\hline 14 & $(3+)$ & & $(3+)$ & & $(3+)$ & & $(-)$ & \\
\hline
\end{tabular}

EMA, epithelial membrane antigen; CEA, carcinoembryonic antigen; E, epithelial component; S, sarcomatous component. Staining grade: $(-)$, positive cells (p) $\leq 5 \% ;(1+), 5 \%<\mathrm{p} \leq 30 \% ;(2+), 30 \%<\mathrm{p} \leq 70 \% ;(3+), \mathrm{p}>70 \%$.

The tissue sections were then incubated with the primary antibody (Table I). After washing with TBS (0.01 M Tris buffered saline, $\mathrm{pH}$ 7.4), the sections were incubated with the peroxidase-labeled polymer from an EnVision ${ }^{+}$system (Dakocytomation) and the color reactions were obtained with 3,3'-diaminobenzidine (Dakocytomation). For the antigen retrieval of E-cadherin, $\beta$-catenin, $\mathrm{N}$-cadherin and TGF- $\beta$, the sections were subjected to microwave treatment for $15 \mathrm{~min}$ with $0.05 \mathrm{M}$ Tris buffer ( $\mathrm{pH} 9.0$ ). For the antigen retrieval of cytokeratin, the sections were incubated with $0.05 \%$ protease (Protease type XXIV) (Sigma, St. Louis, MO, USA) at $37^{\circ} \mathrm{C}$ for $30 \mathrm{~min}$ and then boiled twice for $5 \mathrm{~min}$ each time in $0.01 \%$ citrate buffer ( $\mathrm{pH}$ 6.0). The immunostain was graded according to the proportion of positive cells (p), as follows: (-), $\mathrm{p} \leq 5 \% ;(1+), 5 \%<\mathrm{p} \leq 30 \% ;(2+), 30 \%<\mathrm{p} \leq 70 \% ;(3+), \mathrm{p}>70 \%$.
Statistical analysis. Immunohistochemical positive staining was analyzed using the $\lambda^{2}$ test using Stat Mate III for Windows software (ATMS, Tokyo, Japan). Significance was defined as $\mathrm{p}<0.05$.

\section{Results}

Clinical findings. Table II shows a clinical summary of the $\mathrm{PC}$ patients. The patients were male, ranging in age from 41 to 76 years (mean 62.6). PCs 1, 9, 3 and 1 were at pStages $\mathrm{Ib}$, IIb, IIIa and IV, respectively. The patients underwent lobectomy, with 3 and 4 patients receiving radiation therapy and chemotherapy, respectively, in addition to the lobectomy. Of the 14 patients, 11 succumbed to the disease during the follow-up period, 10 patients succumbed within 11 months 
Table IV. Expression of adhesion molecules and TGF- $\beta$ in pleomorphic carcinomas and poorly-differentiated adenocarcinomas of the lung.

\begin{tabular}{|c|c|c|c|c|c|c|c|c|}
\hline \multirow[b]{2}{*}{ Case } & \multicolumn{2}{|c|}{ E-cadherin } & \multicolumn{2}{|c|}{$\beta$-catenin } & \multicolumn{2}{|c|}{ N-cadherin } & \multicolumn{2}{|c|}{ TGF- $\beta$} \\
\hline & $\mathrm{E}$ & $\mathrm{S}$ & $\mathrm{E}$ & $\mathrm{S}$ & $\mathrm{E}$ & $\mathrm{S}$ & $\mathrm{E}$ & $\mathrm{S}$ \\
\hline \multicolumn{9}{|c|}{ Pleomorphic carcinoma } \\
\hline 1 & $(-)$ & $(-)$ & $(3+)$ & $(-)$ & $(-)$ & $(-)$ & $(3+)$ & $(2+)$ \\
\hline 2 & $(-)$ & $(-)$ & $(-)$ & $(-)$ & $(-)$ & $(-)$ & $(2+)$ & $(+)$ \\
\hline 3 & $(-)$ & $(-)$ & $(3+)$ & $(1+)$ & $(2+)$ & $(1+)$ & $(-)$ & $(-)$ \\
\hline 4 & $(2+)$ & $(1+)$ & $(-)$ & $(-)$ & $(-)$ & $(-)$ & $(3+)$ & $(3+)$ \\
\hline 5 & $(3+)$ & $(1+)$ & $(3+)$ & $(1+)$ & $(-)$ & $(2+)$ & $(2+)$ & $(2+)$ \\
\hline 6 & $(-)$ & $(-)$ & $(-)$ & $(1+)^{\mathrm{a}}$ & $(-)$ & $(1+)$ & $(-)$ & $(-)$ \\
\hline 7 & $(-)$ & $(-)$ & $(-)$ & $(-)$ & $(-)$ & $(-)$ & $(2+)$ & $(2+)$ \\
\hline 8 & $(2+)$ & $(-)$ & $(-)$ & $(-)$ & $(-)$ & $(-)$ & $(3+)$ & $(1+)$ \\
\hline 9 & $(-)$ & $(-)$ & $(-)$ & $(-)$ & $(3+)$ & $(3+)$ & $(-)$ & $(1+)$ \\
\hline 10 & $(1+)$ & $(-)$ & $(-)$ & $(-)$ & $(2+)$ & $(2+)$ & $(-)$ & $(-)$ \\
\hline 11 & $(-)$ & $(-)$ & $(-)$ & $(-)$ & $(-)$ & $(-)$ & $(2+)$ & $(-)$ \\
\hline 12 & $(1+)$ & $(-)$ & $(-)$ & $(-)$ & $(-)$ & $(-)$ & $(2+)$ & $(2+)$ \\
\hline 13 & $(3+)$ & $(-)$ & $(-)$ & $(-)$ & $(-)$ & $(-)$ & $(1+)$ & $(-)$ \\
\hline 14 & $(-)$ & $(-)$ & $(3+)$ & $(-)$ & $(1+)$ & $(-)$ & $(3+)$ & $(2+)$ \\
\hline \multicolumn{9}{|c|}{ Poorly differentiated adenocarcinoma } \\
\hline 1 & $(3+)$ & & $(3+)$ & & $(2+)$ & & $(2+)$ & \\
\hline 2 & $(3+)$ & & $(3+)$ & & $(-)$ & & $(-)$ & \\
\hline 3 & $(3+)$ & & $(3+)$ & & $(-)$ & & $(-)$ & \\
\hline 4 & $(2+)$ & & $(3+)$ & & $(-)$ & & $(-)$ & \\
\hline 5 & $(3+)$ & & $(2+)$ & & $(-)$ & & $(-)$ & \\
\hline 6 & $(3+)$ & & $(3+)$ & & $(-)$ & & $(2+)$ & \\
\hline 7 & $(-)$ & & $(3+)$ & & $(-)$ & & $(1+)$ & \\
\hline 8 & $(3+)$ & & $(2+)$ & & $(-)$ & & $(1+)$ & \\
\hline 9 & $(3+)$ & & $(3+)$ & & $(-)$ & & $(-)$ & \\
\hline 10 & $(3+)$ & & $(3+)$ & & $(-)$ & & $(-)$ & \\
\hline 11 & $(3+)$ & & $(3+)$ & & $(-)$ & & $(-)$ & \\
\hline 12 & $(3+)$ & & $(3+)$ & & $(-)$ & & $(-)$ & \\
\hline 13 & $(3+)$ & & $(3+)$ & & $(-)$ & & $(-)$ & \\
\hline 14 & $(3+)$ & & $(3+)$ & & $(-)$ & & $(1+)$ & \\
\hline
\end{tabular}

TGF- $\beta$, transforming growth factor- $\beta$; E, epithelial component; S, sarcomatous component. Staining grade: (-), positive cells (p)<5\%; $(1+)$, $5 \%<\mathrm{p} \leq 30 \% ;(2+), 30 \%<\mathrm{p} \leq 70 \% ;(3+), \mathrm{p}>70 \%$. a Nuclear staining.

after the lobectomy regardless of pStage and 1 patient succumbed 11 years after the lobectomy.

Histological findings. The histology of the PCs is shown in Table II. Epithelial components of the PCs consisted of poorly differentiated adenocarcinoma (Fig. 1A). Sarcomatous components of 4, 3 and 7 PCs contained spindle tumor cells only (Fig. 1B), giant tumor cells only (Fig. 1C) and spindle and giant tumor cells, respectively.

Immunohistochemical findings. Table III shows the expression of epithelial markers such as cytokeratin, EMA and CEA, as well as a mesenchymal marker, vimentin, in PCs and poorly differentiated adenocarcinomas. Cytokeratin, EMA and CEA were expressed in epithelial components of 12, 11 and 7 of 14 PCs, respectively. The epithelial components of the PCs expressed cytokeratin or EMA. The expression of vimentin was found in the epithelial component of 1 of 14 PCs. Cytokeratin, EMA and CEA were expressed in sarcomatous components of 10,10 and 4 of 14 PCs. Sarcomatous components of 12 of 14 PCs expressed cytokeration or EMA. Sarcomatous components of PCs except one PC expressed cytokeration, EMA or CEA. Cytokeratin, EMA and CEA were expressed in 14, 13 and 12 of 14 poorly differentiated adenocarcinomas. Vimentin was not expressed in all poorly differentiated adenocarcinomas. The expression of adhesion molecules and TGF- $\beta$ in PCs and poorly differentiated adenocarcinomas is shown in Table IV. Positive staining of E-cadherin, $\beta$-catenin 


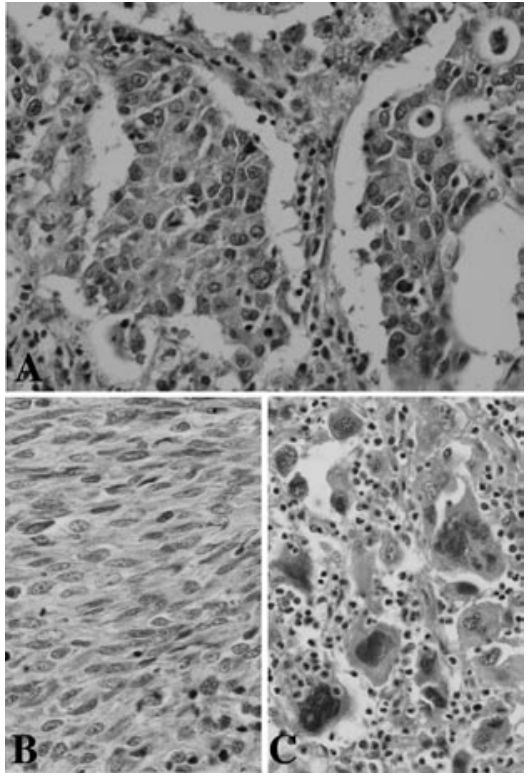

Figure 1. Epithelial and sarcomatous components of a pleomorphic carcinoma. Hematoxylin and eosin staining. Magnification, x400. (A) An epithelia component showing the histology of poorly differentiated adenocarcinoma. (B) spindle cells and (C) giant cells in a sarcomatous component are shown. and $\mathrm{N}$-cadherin was found on the membrane of tumor cells (Fig. 2), whereas TGF- $\beta$ was positively stained in the cytoplasm of tumor cells (Fig. 3). A sarcomatous component of one PC only showed both membranous and nuclear staining of $\beta$-catenin. Table $\mathrm{V}$ shows the comparison of incidences of the expression of adhesion molecules and TGF- $\beta$ at the $2+$ and 3+ staining grades among epithelial and sarcomataous components of $\mathrm{PCs}$ and poorly differentiated adenocarcinomas. The incidences of the expression of E-cadherin and $\beta$-catenin at the 2+ and 3+ staining grade are significantly higher in poorly differentiated adenocarcinomas than in epithelial or sarcomatous components of PCs. The incidence of the expression of TGF $-\beta$ at the $2+$ and $3+$ staining grades was significantly lower in poorly differentiated adenocarcinomas than in epithelial components of PCs. No significant difference in the expression of E-cadherin, $\beta$-catenin and TGF- $\beta$ at the $2+$ and $3+$ staining grades was found between sarcomatous and epithelial components of PCs. No significant difference was noted in an incidence of the expression of $\mathrm{N}$-cadherin at the $2+$ and $3+$ staining grades among poorly differentiated adenocarcinomas and epithelial and sarcomatous components of PCs.

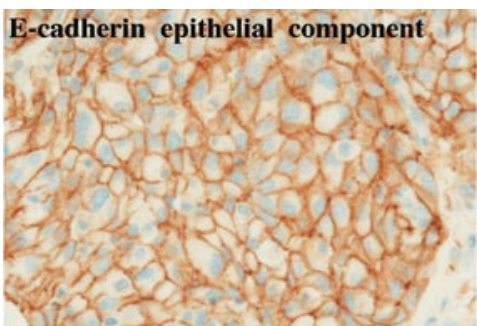

A

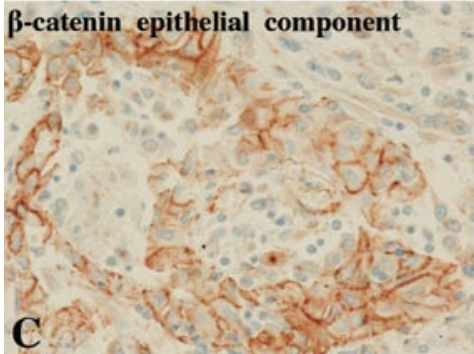

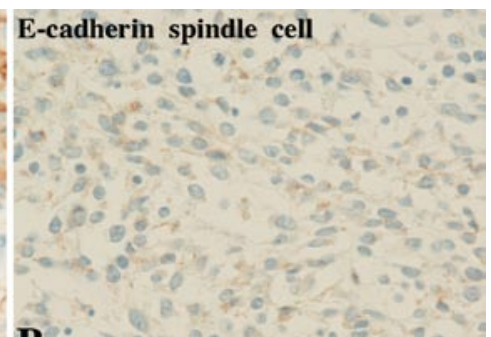

B

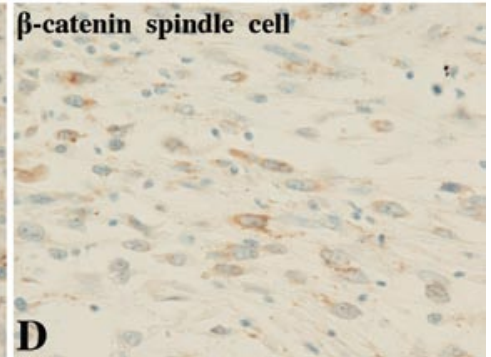

Figure 2. Immunohistochemical stain for E-cadherin and $\beta$-catenin. Magnification, $x 400$. (A) and (C) Positive staining for E-cadherin and $\beta$-catenin in epithelial components of PCs, respectively. (B) and (D) Positive staining for E-cadherin and $\beta$-catenin in sarcomatous components of PCs, respectively. Staining grades for A, B, C and D are $3+, 1+, 3+$ and $1+$, respectively.

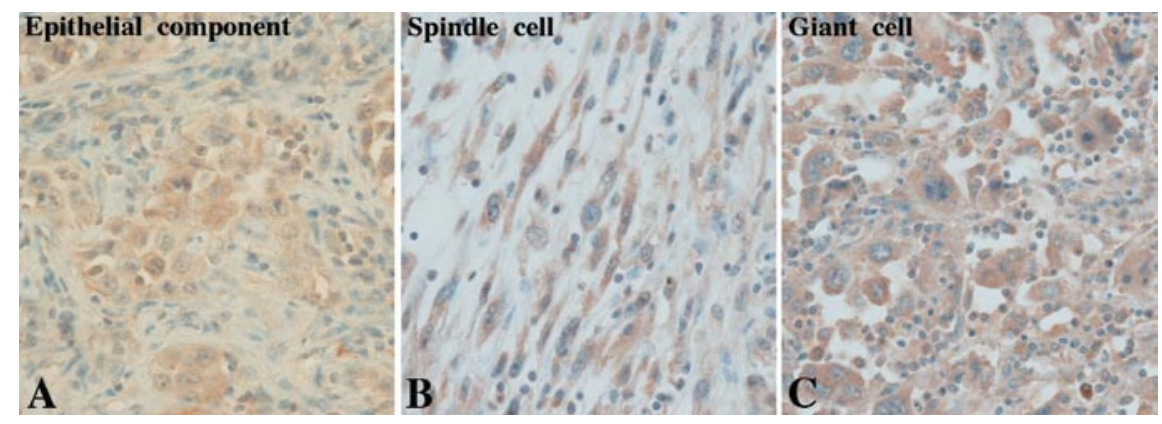

Figure 3. Immunohistochemical stain for TGF- $\beta$. Magnification, $x 400$. (A), (B) and (C) Positive staining for TGF- $\beta$ at the staining grade $3+$ in an epithelial component of a PC, and spindle and giant cells in sarcomatous components of PCs, respectively. 
Table V. Expression of adhesion molecules and TGF- $\beta$ at $2+$ and $3+$ staining grades in pleomorphic carcinomas and poorly differerentiated adenocarcinomas of the lung.

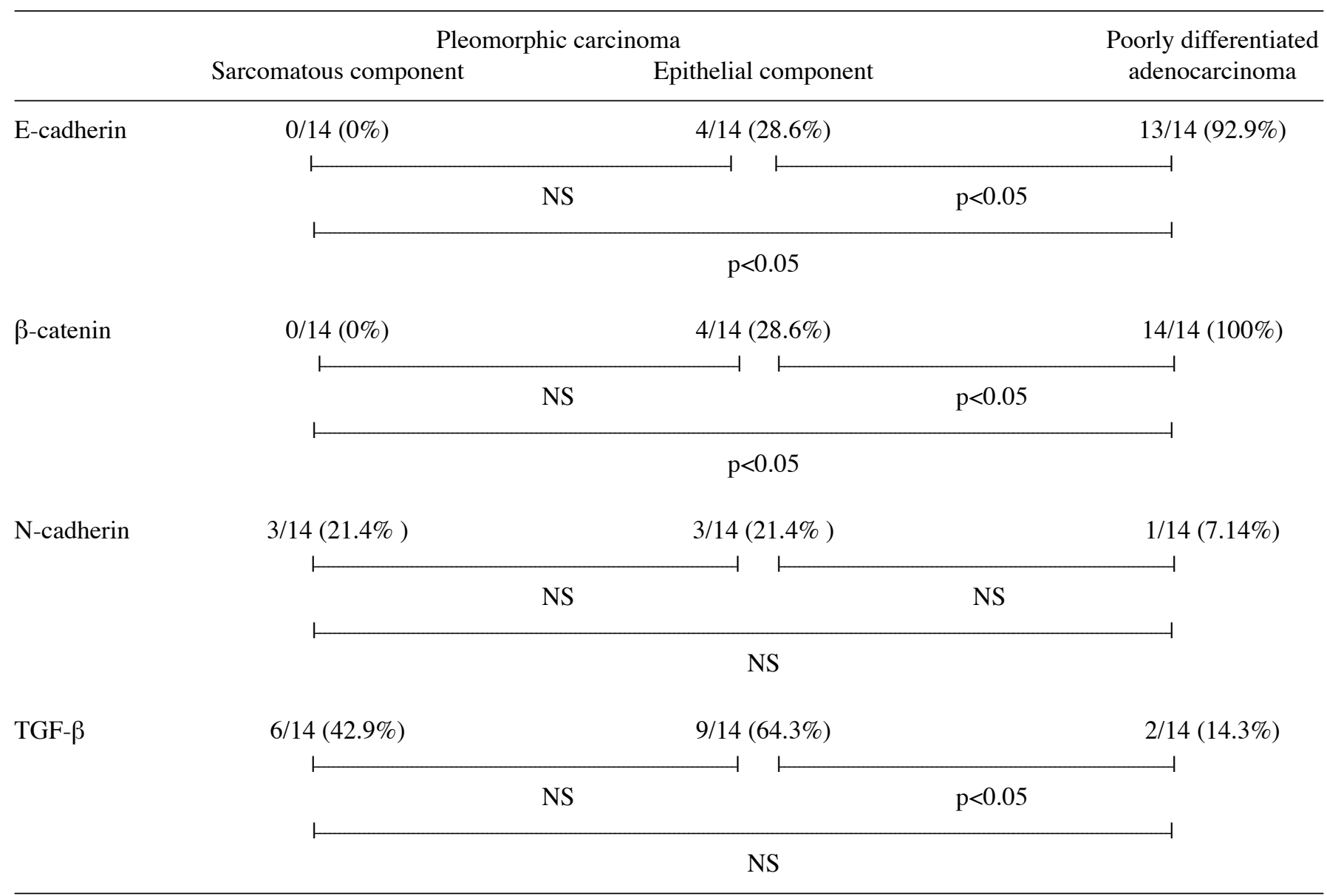

TGF- $\beta$, transforming growth factor- $\beta$; NS, not significant.

\section{Discussion}

The follow-up data of the PC patients showed that 10 of 11 patients who died of $\mathrm{PC}$ succumbed to the disease within a year after the lobectomy and one patient succumbed 11 years after the lobectomy. The follow-up data confirmed poor prognosis of patients with PCs, as previously reported $(2,3)$.

A sarcomatous component of $\mathrm{PC}$ is considered to represent the sarcomatous change of cancer cells in an epithelial component (1). This change is supported by the immunohistochemical and ultrastructural identification of epithelial features in a sarcomatous component and by identical gene mutations in epithelial and sarcomatous components $(1,23)$. The immunohistochemical results of the present study also confirmed the expression of epithelial markers, such as cytokeratin, EMA and CEA, in sarcomatous components in 13 of 14 PCs, thus supporting the epithelial origin of tumor cells in a sarcomatous component of PC.

It has been reported that the $\mathrm{N}$-cadherin expression is uncommon in adenocarcinomas of the lung and is not a prognostic factor thereof $(24,25)$. In the present study, incidences of $\mathrm{N}$-cadherin expression were also low in poorly differentiated adenocarcinomas, as well as in epithelial and sarcomatous components of PCs. Additionally, no significant difference was noted in the $\mathrm{N}$-cadherin expression among the adenocarcinomas and components of PC. These results suggest that the aggressiveness of PCs is not associated with $\mathrm{N}$-cadherin expression.

The E-cadherin and $\beta$-catenin expression was reduced, while the TGF- $\beta$ expression was increased in epithelial and sarcomatous components of PCs compared to poorly differentiated adenocarcimonas, although the epithelial components of PCs showed the same histology as poorly differentiated adenocarcinomas. Numerous studies showed that the loss or reduction of the E-cadherin- $\beta$-catenin complex is associated with metastasis and a poor prognosis in non-small cell carcinomas of the lung $(5,6,26,27)$. Moreover, the TGF- $\beta$ expression was reported to be associated with poor prognosis of patients with adenocarcinomas of the lung $(18,19)$. Therefore, the reduced expression of E-cadherin and $\beta$-catenin and the increased expression of TGF- $\beta$ in PCs appear to be associated with the aggressiveness of PCs. Furthermore, although the histology is the same, the different expression of the three molecules between epithelial components of PCs and poorly differentiated adenocarcinomas appears to reflect their different nature. On the other hand, TGF- $\beta$ has been reported to be an inducing factor of the epithelial-mesenchymal transition in which cancer cells lose the epithelial phenotype and acquire the 
mesenchymal phenotype, thereby becoming more aggressive (13-17). Therefore, TGF- $\beta$ may play a role in the generation of spindle or giant cells in a sarcomatous component from cancer cells in an epithelial component in PCs.

Przygodzki et al (4) showed that mutation frequencies and patterns for p53 and K-ras were different between the epithelial components of PCs and non-small cell carcinomas, indicating that $\mathrm{PC}$ is distinct from non-small cell carcinoma of the lung. In agreement with this study, the present results showed that the expression of E-cadherin, $\beta$-catenin and TGF- $\beta$ was different between poorly differentiated adenocarcinomas and the epithelial components of PCs showing the same histology as poorly-differentiated adenocarcinoma. It is generally accepted that a sarcomatous component of PC develops from an epithelial component of PC $(1,23)$. However, $\mathrm{PC}$ is not a tumor of non-small cell carcinoma of the lung with a sarcomatous change.

\section{References}

1. Corrin B, Wick MR, Chang YL, et al: Sarcomatoid carcinoma. In: Pathology and Genetics, Tumors of the Lung, Pleura, Thymus and Heart, World Health Organization Classification of Tumours Travis WD, Brambilla E, Müller-Hermelink HK and Harris CC (eds). IARC Press, Lyon, pp53-58, 2004.

2. Wick MR, Ritter JH and Humphrey PA: Sarcomatoid carcinomas of the lung: a clinicopathologic review. Am J Clin Pathol 108 40-53, 1997.

3. Mochizuki T, Ishii G, Nagai K, et al: Pleomorphic carcinoma of the lung. Clinicopathologic characteristics of 70 cases. Am J Surg Pathol 32: 1727-1735, 2008.

4. Przygodzki RM, Koss MN, Moran CA, et al: Pleomorphic (giant and spindle cell) carcinoma is genetically distinct from adenocarcinoma and squamous cell carcinoma by K-ras-2 and p53 analysis. Am J Clin Pathol 106: 487-492, 1996.

5. Bremnes RM, Veve R, Hirsch FR and Franklin WA: The E-cadherin cell-cell adhesion complex and lung cancer invasion, metastasis, and prognosis. Lung Cancer 36: 115-124, 2002.

6. Charalabopoulos K, Gogali A, Kostoula OK and Constantopoulos SH: Cadherin superfamily of adhesion molecules in primary lung cancer. Exp Oncol 26: 256-260, 2004.

7. Jeanes A, Gottardi CJ and Yap AS: Cadherins and cancer: how does cadherin dysfunction promote tumor progression? Oncogene 27: 6920-6929, 2008.

8. Makrilla N, Kollias A, Manolopoulos L and Syrigos K: Cell adhesion molecules: role and clinical significance in cancer. Cancer Invest 27: 1023-1037, 2009.

9. Nieman MT, Prudoff RS, Johnson KR and Wheelock MJ: $\mathrm{N}$-cadherin promotes motility in human breast cancer cells regardless of their E-cadherin expression. J Cell Biol 147: 631-644, 1999.

10. Hazan RB, Phillips GR, Qiao RF, Norton L and Aaronson SA Exogenous expression of $\mathrm{N}$-cadherin in breast cancer cells induces cell migration, invasion, and metastasis. J Cell Biol 148 779-790, 2000.
11. Li G, Satyamoorthy $\mathrm{K}$ and Herlyn $\mathrm{M}$ : N-cadherin-mediated intercellular interactions promote survival and migration of melanoma cells. Cancer Res 61: 3819-3825, 2001.

12. Cavallaro U: N-cadherin as an invasion promoter: a novel target for antitumor therapy? Curr Opin Investig Drugs 5: 1274-1278, 2004.

13. Voulgari A and Pintzas A: Epithelial-mesenchymal transition in cancer metastasis: mechanisms, markers and strategies to overcome drug resistance in the clinic. Biochim Biophys Acta 1976: 75-90, 2009.

14. Kalluri R and Weinberg RA: The basics of epithelial-mesenchymal transition. J Clin Invest 119: 1420-1428, 2009.

15. Iwatsuki M, Mimori K, Yokobori T, et al: Epithelial-mesenchymal transition in cancer development and its clinical significance. Cancer Sci 101: 293-299, 2010.

16. Rees JRE, Onwuegbusi BA, Save VE, Alderson D and Fitzgerald RC: In vivo and in vitro evidence for transforming growth factor- $\beta 1$-mediated epithelial to mesenchymal transition in esophageal adenocarcinoma. Cancer Res 66: 9583-9590, 2006.

17. Kaimori A, Potter J, Kaimori JY, Wang C, Mezey E and Koteish A: Transforming growth factor- $\beta 1$ induces an epithelialto-mesenchymal transition state in mouse hepatocytes in vitro. $\mathrm{J}$ Biol Chem 282: 22089-22101, 2007.

18. Takanami I, Imamura T, Hashizume T, Kikuchi K, Yamamoto Y and Kodaira S: Transforming growth factor- $\beta 1$ as a prognostic factor in pulmonary adenocarcinoma. J Clin Pathol 47: 1098-1100, 1994.

19. Takanami I, Imamura T, Hashizume T, Kikuchi K, Yamamoto $Y$, Yamamoto T and Kodaira S: Expression of PDGF, IGF-II and TGF- $\beta 1$ in pulmonary adnocarcinoma. Pathol Res Pract 192: 1113-1120, 1996.

20. Robson H, Anderson E, James RD and Schofield RF: Transforming growth factor $\beta 1$ expression in human colorectal tumours: an independent prognostic marker in a subgroup of poor prognosis patients. Br J Cancer 74: 753-758, 1996.

21. Saito H, Tsujitani S, Oka S, Kondo A, Ikeguchi M, Maeta M and Kaibara N: The expression of transforming growth factor- $\beta 1$ is significantly correlated with the expression of vascular endothelial growth factor and poor prognosis of patients with advanced gastric carcinoma. Cancer 86: 1455-1462, 1999.

22. Desruisseau S, Palmari J, Giusti C, Romain S, Martin PM and Berthois Y: Determination of TGF $\beta 1$ protein level in human primary breast cancers and its relationship with survival. Br J Cancer 94: 239-246, 2006.

23. Pelosi G, Scarpa A, Manzotti M, et al: K-ras gene mutational analysis supports a monoclonal origin of biphasic pleomorphic carcinoma of the lung. Mod Pathol 17: 538-546, 2004.

24. Nakashima T, Huang C, Liu D, et al: Neural-cadherin expression associated with angiogenesis in non-small-cell lung cancer patients. Br J Cancer 88: 1727-1733, 2003.

25. Zynger DL, Dimov ND, Ho LC, Laskin WB and Yeldandi AV: Differential expression of neural-cadherin in pulmonary epithelial tumours. Histopathology 52: 348-354, 2008.

26. Kase S, Sugio K, Yamazaki K, Okamoto T, Yano $T$ and Sugimachi K: Expression of E-cadherin and $\beta$-catenin in human non-small cell lung cancer and the clinical significance. Clin Cancer Res 6: 4789-4796, 2000.

27. Nozawa N, Hashimoto S, Nakashima Y, et al: Immunohistochemical $\alpha$ - and $\beta$-catenin and E-cadherin expression and their clinicopathological significance in human lung adenocarcinoma. Pathol Res Pract 202: 639-650, 2006. 